\title{
[Letter to the Editor] \\ Influence of clotting duration on brain-derived neurotrophic factor (BDNF) dosage in serum
}

Brain-derived neurotrophic factor (BDNF) is the most abundant and widely distributed neurotrophin in the central nervous system. BDNF is implicated in several neurodevelopmental functions (1), but it also takes part in nervous system maintenance during adulthood (2).

BDNF is expressed also in peripheral blood, where it is mostly stored in platelets (3); based on this, several studies have evaluated serum BDNF levels in patients affected by different diseases. This research field has been growing considerably in recent years; in particular, alterations of BDNF levels in serum have been described in psychiatric and neurodegenerative diseases. Serum BDNF could therefore represent a valuable peripheral biomarker for such pathologies, with the advantage of being measurable in vivo with noninvasive methods.

However, in a meta-analysis comprising 15 papers on major depression published from 2002 to 2010, we reported that serum BDNF concentrations show a considerable variability between different studies. In healthy subjects, BDNF levels range from $12.2 \pm 2.4$ [mean \pm standard deviation (sD)] to $64.1 \pm 13.1 \mathrm{ng} / \mathrm{mL}$ (4). Similar evidence also emerges from other meta-analyses on bipolar disorder (range: $13.4 \pm 0.91$ to $42.5 \pm$ $12.5 \mathrm{ng} / \mathrm{mL}$ ) (5) and anxiety disorders (range: $9.49 \pm 3.18$ to $41.59 \pm 7.82 \mathrm{ng} /$ $\mathrm{mL}$ (6). In addition to nontechnical factors already known to affect serum BDNF levels, such as age, smoking, drinking, fasting, time of sampling, physical activity, and living in an urban environment $(7,8)$, this variability could be attributed to different methodological procedures for serum preparation and storage conditions. Indeed, the duration of serum storage, both at $-20^{\circ} \mathrm{C}$ and $-80^{\circ} \mathrm{C}$, was demonstrated to be inversely correlated with measured BDNF levels, due to the progressive activity of proteoIytic enzymes $(9,10)$. Furthermore, the duration and temperature of clotting and the duration and speed of centrifugation, which are highly variable between different studies, are likely to affect the measurement of BDNF levels. In particular, because BDNF is stored in platelets, clotting duration could constitute a critical issue for its dosage in serum. In the studies published so far, the clotting duration varies from $30 \mathrm{~min}$ to $3 \mathrm{hr}$, when specified, but it is often not clearly stated (expressions such as "blood was allowed to clot" are used). The only study that evaluated this issue was conducted in rats by measuring serum BDNF after increasing clotting durations. Stable BDNF levels were described from 1 to $24 \mathrm{hr}$ of clotting, but earlier time points were not evaluated (11).

Due to the preceding concerns, in the present study we investigated the influence of clotting duration on BDNF levels in human serum, both at early and late time points, to determine the time course of BDNF release from platelets and to help to establish a standardized procedure for its dosage.

Ten healthy volunteers (8 females and 2 males, mean age $32.3 \pm$ SD 7.3 years) were enrolled in the study, and 5 venous blood samples for each subject were drawn in the morning in anticoagulant-free tubes. Each tube was kept at room temperature for 10 min, 30 min, 1 hr, 2 hr, or 5 hr. For 5 subjects, a sixth sample was collected to test clotting conditions of $1 \mathrm{hr}$ at room temperature followed by $1 \mathrm{hr}$ at $4^{\circ} \mathrm{C}$. Serum separation was subsequently obtained by centrifugation at $1620 \times g$ for $15 \mathrm{~min}$ at room temperature. Serum samples were immediately stored at $-80^{\circ} \mathrm{C}$ until the time of assay. BDNF levels were measured within 1 month with enzyme-linked immunosorbent assay (ELISA) (BDNF DuoSet kit, R\&D Systems, Minneapolis, $M N$ ), in duplicate. BDNF content was

Table 1. Serum BDNF measurement values at different clotting durations and means \pm standard deviations $(\mathrm{ng} / \mathrm{ml})$.

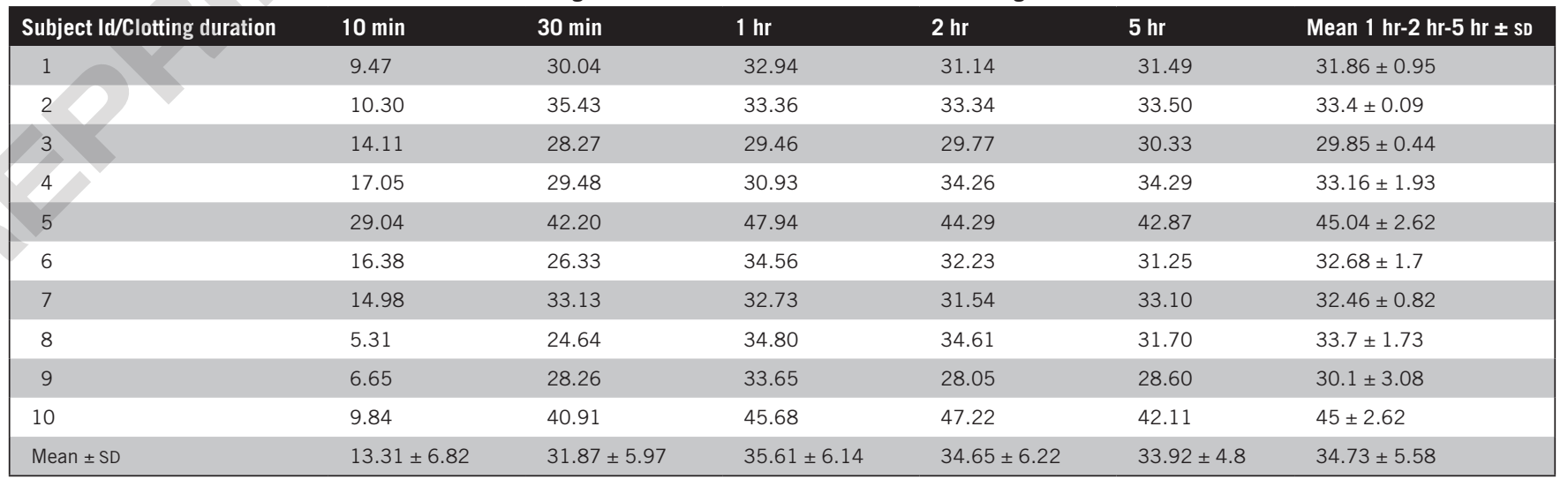


expressed as nanograms of protein per milliliter $(\mathrm{ng} / \mathrm{mL}$ ) of serum, taking into account the dilution factor used (1:100), with a detection limit of $20 \mathrm{pg} /$ $\mathrm{mL}$.

The mean BDNF concentration determined in serum after 10 min of clotting at room temperature was $13.31 \pm 6.82 \mathrm{ng} /$ $\mathrm{mL}$, increasing to $31.87 \pm 5.97$ $\mathrm{ng} / \mathrm{mL}$ after $30 \mathrm{~min}$ and to 35.61 $\pm 6.14 \mathrm{ng} / \mathrm{mL}$ after $1 \mathrm{hr}$. Thereafter, the measurements appeared stable: $34.65 \pm 6.22$ and $33.92 \pm$ $4.8 \mathrm{ng} / \mathrm{mL}$ after $2 \mathrm{hr}$ and $5 \mathrm{hr}$, respectively. For the further clotting condition of $1 \mathrm{hr}$ at room temperature followed by $1 \mathrm{hr}$ at $4^{\circ} \mathrm{C}$, the results were strictly similar to those obtained after $1 \mathrm{hr}$ at room temperature (data not shown). To obtain a statistical assessment of these variations, a repeated-measures analysis of variance (rANOVA) was performed through the Statistical Package for the Social Sciences (SPSS) Version 17 (IBM Corp., Armonk, NY), comparing concentrations at 10 min, $30 \mathrm{~min}, 2 \mathrm{hr}$, and $5 \mathrm{hr}$ to concentrations at $1 \mathrm{hr}$. Significant differences were observed at $10 \mathrm{~min}(P=2.97 \times$ $\left.10^{-6}\right)$ and $30 \mathrm{~min}(P=0.01)$, whereas no modifications were evident at $2 \mathrm{hr}$ $(P=0.27)$ and $5 \mathrm{hr}(P=0.09)$. The mean value $( \pm S D)$ of the quantifications at $1 \mathrm{hr}, 2 \mathrm{hr}$, and $5 \mathrm{hr}$ was $34.73 \pm 5.58$ $\mathrm{ng} / \mathrm{mL}$; compared to this plateau value, the mean levels at $10 \mathrm{~min}$ and $30 \mathrm{~min}$ were $38 \%$ and $91.8 \%$, respectively. Single-subject measurement values and means $( \pm S D)$ are reported in Table 1. In Figure 1A, the time course of BDNF level for every subject is shown, whereas the mean BDNF concentration ( $\pm \mathrm{SD}$ ) for every clotting duration is represented in Figure 1B.

Peripheral BDNF represents a potentially highly valuable biomarker, which could help in the diagnosis and prognosis of psychiatric and neurodegenerative diseases, as well as in the prediction of treatment response and the evaluation of therapeutic effectiveness. To date, more than 400 articles have been published investigating serum BDNF levels in different pathological conditions. A major issue with these studies concerns the methodological aspects, because different meta-analyses reported a considerable variability in serum BDNF concentrations in healthy subjects between different studies (4-6), possibly due to different technical procedures for serum preparation and storage conditions. Because BDNF is stored in platelets, the main variable likely to affect BDNF dosage is the duration of the clotting process. We have investigated the influence of increasing clotting durations at room temperature, observing a progressive enhancement of serum BDNF content: the concentrations reached $38 \%$ of the plateau value after $10 \mathrm{~min}, 91.8 \%$ after $30 \mathrm{~min}$, and $100 \%$ after $1 \mathrm{hr}$, probably reflecting the kinetics of BDNF release from platelets; additional resting for $1 \mathrm{hr}$ at $4^{\circ} \mathrm{C}$ had no effect. Therefore, we recommend $1 \mathrm{hr}$ as the minimum clotting duration for a correct serum BDNF dosage.

\section{Author contributions}

L.B.-C., E.M. and M.G. designed the experiment. E.M. and R.Z. arranged and performed blood collection, serum preparation, and BDNF measurement. E.M. and L.B.-C. analyzed the results. E.M. and L.B.-C. wrote the paper. M.G. and R.Z. revised the paper.

\section{Acknowledgments}

Funding for this study was provided by the Italian Ministry of Health (Ricerca Corrente). We want to sincerely thank all the volunteers who participated in this study

\section{Competing interests}

The authors declare no competing interests.

\section{References}

1. Martinowich, K. and B. Lu. 2008. Interaction between BDNF and serotonin: role in mood disorders. Neuropsychopharmacology 33:73-83.

2. Lu, Y., K. Christian, and B. Lu. 2008. BDNF: a key regulator for protein synthesis-dependent LTP and long-term memory? Neurobiol. Learn. Mem. 89:312-323

3. Fujimura, H., C.A. Altar, R. Chen, T. Nakamura, T. Nakahashi, J. Kambayashi, B.
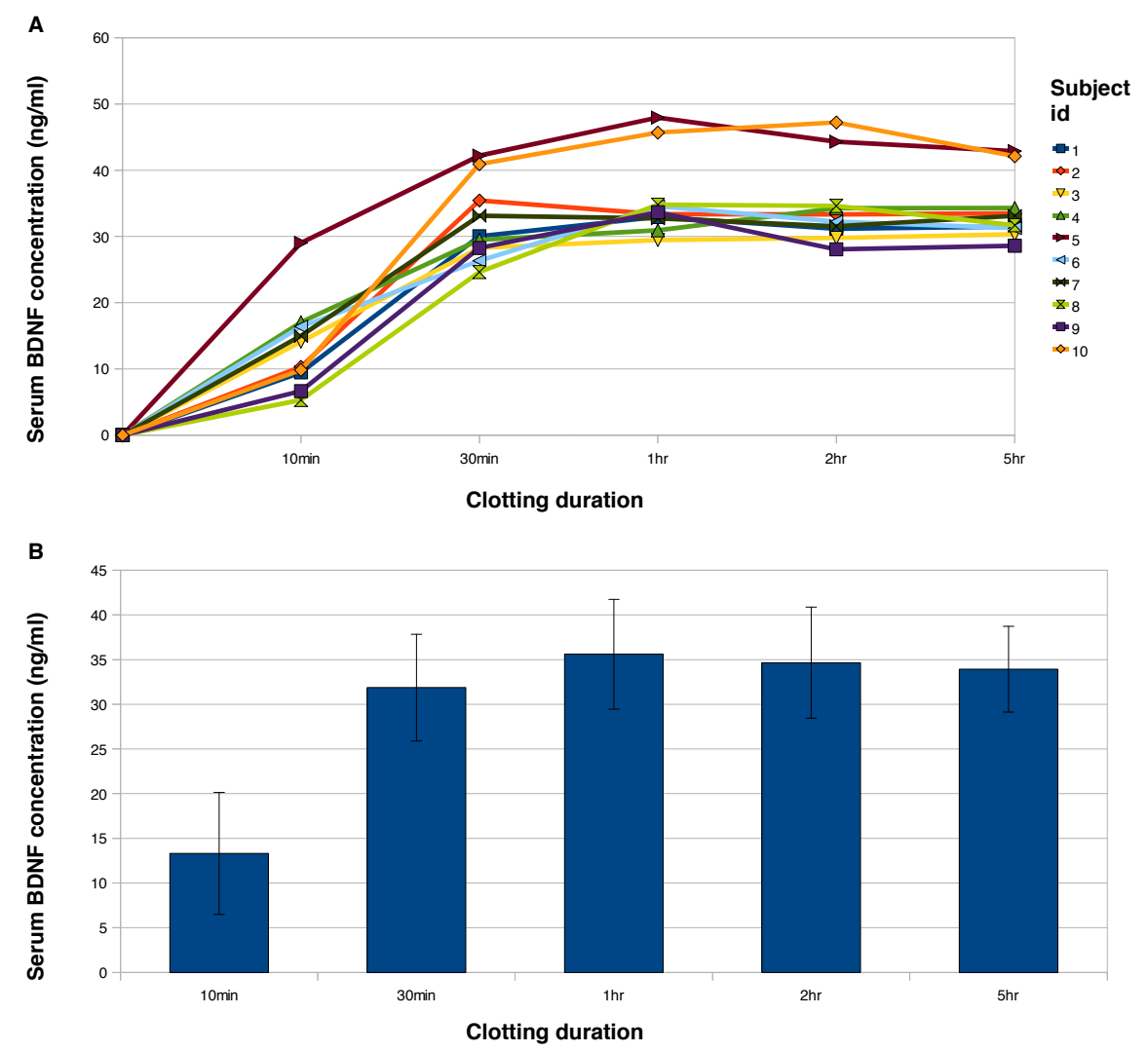

Figure 1. Influence of clotting duration on BDNF concentration. (A) Time course of BDNF concentration for every subject. (B) Mean BDNF concentration \pm standard deviation for every clotting duration. 
Sun, and N.N. Tandon. 2002. Brain-derived neurotrophic factor is stored in human platelets and released by agonist stimulation. Thromb. Haemost. 87:728-734.

4. Bocchio-Chiavetto, L., V. Bagnardi, R. Zanardini, R. Molteni, M.G. Nielsen, A. Placentino, C. Giovannini, L. Rillosi, et al. 2010. Serum and plasma BDNF levels in major depression: a replication study and metaanalyses. World J. Biol. Psychiatry 11:763-773.

5. Fernandes, B.S., C.S. Gama, K.M. Ceresér, L.N. Yatham, G.R. Fries, G. Colpo, D. de Lucena, M. Kunz, et al. 2011. Brain-derived neurotrophic factor as a state-marker of mood episodes in bipolar disorders: a systematic review and meta-regression analysis. J. Psychiatr. Res. 45:995-1004.

6. Suliman, S., S.M. Hemmings, and S. Seedat. 2013. Brain-derived neurotrophic factor (BDNF) protein levels in anxiety disorders: systematic review and meta-regression analysis. Front Integr Neurosci. 7:55.

7. Bus, B.A., M.L. Molendijk, B.J. Penninx, J.K. Buitelaar, G. Kenis, J. Prickaerts, B.M. Elzinga, and R.C. Voshaar. 2011. Determinants of serum brain-derived neurotrophic factor. Psychoneuroendocrinology 36:228239.

8. Elfving, B., H.N. Buttenschøn, L. Foldager, P.H. Poulsen, J.H. Andersen, M.B. Grynderup, Å.M. Hansen, H.A. Kolstad, et al. 2012. Depression, the Val66Met polymorphism, age, and gender influence the serum BDNF level. J. Psychiatr. Res. 46:1118-1125.
9. Trajkovska, V., A.B. Marcussen, M. Vinberg, P. Hartvig, S. Aznar, and G.M. Knudsen. 2007. Measurements of brain-derived neurotrophic factor: methodological aspects and demographical data. Brain Res. Bull. 73:143149.

10. Zuccato, C., M. Marullo, B. Vitali, A. Tarditi, C. Mariotti, M. Valenza, N. Lahiri, E.J. Wild, et al. 2011. Brain-derived neurotrophic factor in patients with Huntington's disease. PLoS ONE 6:e22966.

11. Elfving, B., P.H. Plougmann, and G. Wegener. 2010. Detection of brain-derived neurotrophic factor (BDNF) in rat blood and brain preparations using ELISA: pitfalls and solutions. J. Neurosci. Methods 187:73-77.

Received 22 May 2014; accepted 17 July 2014.

BioTechniques 57:111-114 (September 2014) doi 10.2144/000114204

Elisabetta Maffioletti ${ }^{1,2}$, Roberta Zanardini ${ }^{3}$, Massimo Gennarelli, ${ }^{1,2}$ and Luisella Bocchio-Chiavetto ${ }^{3,4}$

${ }^{1}$ Department of Molecular and Translational Medicine, University of Brescia, Brescia, Italy, ${ }^{2}$ Genetics Unit, IRCCS Centro San Giovanni di
Dio, Fatebenefratelli, Brescia, Italy, ${ }^{3}$ Neuropsychopharmacology Unit, IRCCS Centro San Giovanni di Dio, Fatebenefratelli, Brescia, Italy, and ${ }^{4}$ Faculty of Psychology, eCampus University, Novedrate, Como, Italy

Address correspondence to Luisella BocchioChiavetto, Neuropsychopharmacology Unit, IRCCS Centro San Giovanni di Dio, Fatebenefratelli, Brescia, Italy. E-mail: luisellabocchio@gmail.com

To purchase reprints of this article, contact: biotechniques@fosterprinting.com

\section{A NEW STANDARD IN RNA ISOLATION}

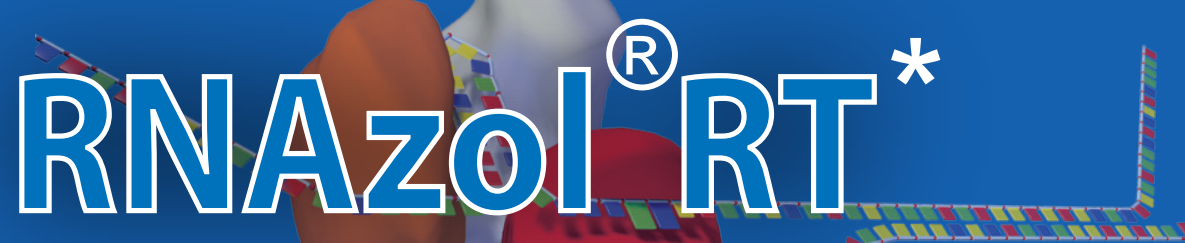

Isolates total RNA, with MRNA and small RNA (200-10 bases) in separate fraction

\section{THE HIGHEST YIELD AND PURITY:}

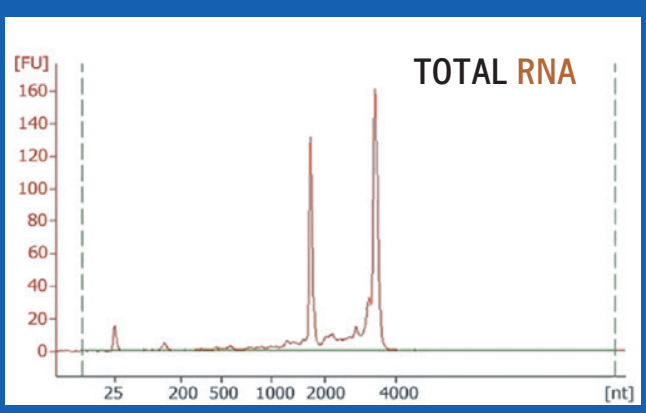

The single-step method without phase separation

$\checkmark$ No DNase treatment necessary

$\checkmark$ RNA ready for RT-PCR, microarrays and other applications

$\checkmark$ No need for refrigerated centrifuge

$\checkmark$ One reagent for solid and liquid samples

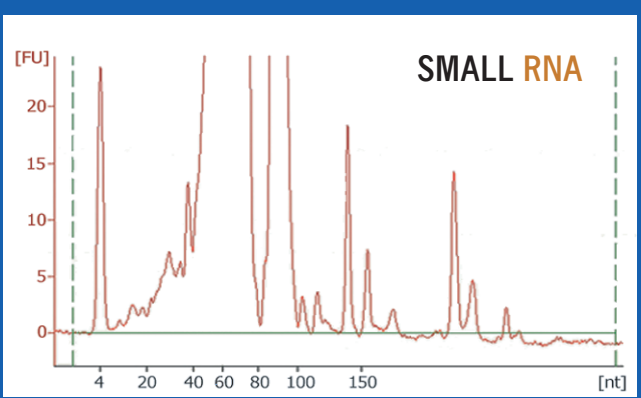

